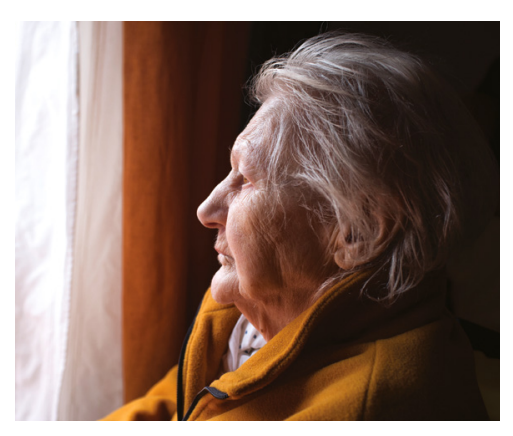

CPD

Edwin CK Tan, Sarah N Hilmer, Sara Garcia-Ptacek, J Simon Bell

\section{Background}

Alzheimer's disease is the most common form of dementia and is a major contributor to morbidity and mortality in older Australians.

\section{Objectives}

The aim of this article is to provide an overview of available pharmacological therapies for the symptomatic treatment of Alzheimer's disease.

\section{Discussion}

Acetylcholinesterase inhibitors (AChEls) or memantine may be trialled in people with Alzheimer's disease to delay symptoms of cognitive and functional decline. The choice of pharmacological agent is based on the stage of Alzheimer's disease, tolerability, adverse effect profile, ease of use and cost. People should be monitored for efficacy, side effects and possible treatment discontinuation. Strategies should be used to optimise medication management and adherence. Evidence for other pharmacological therapies is mixed or lacking. Behavioural and psychological symptoms of dementia (BPSD) are common in people with Alzheimer's disease and may respond to symptomatic pharmacological and nonpharmacological treatment.

\title{
Current approaches to the pharmacological treatment of Alzheimer's disease
}

THERE ARE ABOUt 425,400 Australians living with dementia and this is expected to increase to over one million by $2056 .^{1,2}$ Dementia is the second leading cause of death and the single greatest cause of disability in older Australians. ${ }^{3}$ Dementia is estimated to cost Australia more than $\$ 15$ billion each year. ${ }^{2}$

Alzheimer's disease is the most common form of dementia, affecting up to $70 \%$ of all people with dementia. ${ }^{4}$ Accumulation of beta-amyloid peptide and intracellular tau protein appear to be central to the degenerative changes in Alzheimer's disease. These result in the destruction of neurones, including cholinergic neurones, and a fall in acetylcholine concentration. ${ }^{5}$ None of the available medications prevents Alzheimer's disease or modifies its pathology. However, medications may be used in conjunction with nonpharmacological treatments to manage cognition, function and behaviour. This article will focus on pharmacological approaches to managing Alzheimer's disease, with a focus on practice points and common adverse events.

\section{Current pharmacological therapies}

Currently, there are two classes of medications used in the treatment of Alzheimer's disease: acetylcholinesterase inhibitors (AChEIs) and memantine, an N-methyl-D-aspartate (NMDA) receptor antagonist. A summary of the dosing schedules, available products and treatment recommendations is reported in Tables 1 and 2.

\section{Acetylcholinesterase inhibitors}

AChEIs decrease the breakdown of acetylcholine, thereby reducing the apparent deficiency of cholinergic neurotransmitter activity. They are indicated for the treatment of mild-tomoderate Alzheimer's disease. To be eligible for a Pharmaceutical Benefit Scheme (PBS) subsidy, the diagnosis must be confirmed by, or made in consultation with, a medical specialist such as a geriatrician, neurologist or psychiatrist. Additionally, the person with Alzheimer's disease must have a Mini-Mental State Examination (MMSE) or standardised MMSE score of $\geq 10$.

Currently available AChEIs include donepezil, galantamine and rivastigmine. A meta-analysis reported that all three AChEIs have similar efficacy and safety. ${ }^{6}$ Choice of AChEIs is based on ease of use, tolerability, cost, and clinician and patient preference. Some people who are unresponsive to one AChEI may appear to stabilise or, rarely, improve when switched to another. ${ }^{7}$ In particular, people who are unresponsive to selective AChEIs may benefit from switching to a dual AChEbutyrylcholinesterase inhibitor (BuChEI) such as rivastigmine. ${ }^{8}$

\section{Contraindications and precautions} AChEIs are contraindicated in people with gastrointestinal (GI) or ureteric obstruction, or active peptic ulcer. ${ }^{9}$ It is recommended that AChEIs be used 
with caution in people with a history of peptic ulcer disease, seizures, heart block, bradyarrhythmias (including sick sinus syndrome), asthma and obstructive pulmonary disease.

The concurrent use of AChEIs with medications with anticholinergic properties should be avoided, given conflicting mechanisms of action and the potential to antagonise therapeutic effects. ${ }^{10}$ However, Australian and North American studies published over the past decade suggest that over one-third of AChEI users are co-prescribed an anticholinergic medication, which is often the result of prescribing cascades. ${ }^{11}$ Other medications that should be used with caution with AChEIs include those that cause bradycardia, as the risk of bradycardia, hypotension and syncope may be increased. ${ }^{12}$

Adverse events are mainly GI-related and include nausea, vomiting and diarrhoea. Toxicity is dose-related and usually resolves with time or dose reduction. Dizziness, drowsiness, bradycardia and syncope may also occur, making older adults more prone to falls and fractures. ${ }^{12}$ Other common adverse effects ( $>1 \%$ ) listed in the Australian medicines handbook include weight loss, anorexia, depression, headache, vivid dreams and muscle cramps. ${ }^{9,13}$ Significant overdose with AChEIs can result in cholinergic crisis, characterised by severe nausea, vomiting, salivation, sweating, bradycardia, hypotension, respiratory depression, collapse and convulsions.

\section{Memantine}

Memantine is an NMDA receptor antagonist that normalises the glutamatergic system and reduces glutamate-induced neuronal degradation in Alzheimer's disease. ${ }^{14}$ Memantine is recommended for people with moderateto-severe Alzheimer's disease who are intolerant of or have a contraindication to AChEIs. ${ }^{15}$ Memantine can be used in combination with AChEI therapy; however, memantine is PBS-subsidised only as a stand-alone therapy in people with an MMSE score of 10-14. Memantine is contraindicated in people with a history of seizures. ${ }^{9}$ It is generally well tolerated; however, adverse effects include GI upset, confusion, dizziness, drowsiness, headache and agitation. ${ }^{9}$

\section{Monitoring efficacy and follow-up}

AChEIs and memantine show modest efficacy in improving cognition and/ or reducing the rate of cognitive and functional decline. ${ }^{16} \mathrm{~A}$ recent metaanalysis of 43 randomised controlled trials (RCTs) involving 16,106 people with Alzheimer's disease found AChEIs led to modest improvements in cognitive function (standardised mean difference $[\mathrm{SMD}]=0.38)$, global symptomatology

\section{Table 1. Medications used in the treatment of Alzheimer's disease}

\begin{tabular}{|c|c|c|c|}
\hline Drug name & Dose forms & Dosing regimen ${ }^{* 9}$ & Clinical notes ${ }^{25}$ \\
\hline
\end{tabular}

Galantamine $\quad$ Capsule Initially $8 \mathrm{mg}$ once daily in the morning for a minimum of four weeks, then $16 \mathrm{mg}$ once daily in the morning for a minimum of four weeks. Max 24 mg daily

\begin{tabular}{ll}
\hline Rivastigmine $\quad$ Capsule & $\begin{array}{l}\text { Initially } 1.5 \mathrm{mg} \text { twice daily; increase by } 3 \mathrm{mg} \\
\text { daily every two weeks to a maximum of } 6 \mathrm{mg} \\
\text { twice daily }\end{array}$
\end{tabular}

Transdermal patch Patch, initially one patch ( $4.6 \mathrm{mg} / 24$ hours) applied once daily; if tolerated, increase after four weeks to one patch ( $9.5 \mathrm{mg} / 24$ hours) once daily. If necessary, after at least four weeks, increase to maximum dose one patch (13.3 mg/24 hours) once daily
Maximum $16 \mathrm{mg}$ daily with moderate renal or liver impairment

Do not use with severe renal or liver impairment

Give with meals

Slow and cautious titration with renal or liver impairment or low body weight

\section{Can cause rash; rotate sites}

Fewer gastrointestinal side effects than capsule. Maximum dose $4.6 \mathrm{mg} / 24$ hours with mild-tomoderate liver impairment or low body weight

Do not use with severe liver impairment

For conversion from capsules to patch: use patch of closest strength to established oral daily dose. Start patch on the day after the last oral dose

\begin{tabular}{|c|c|}
\hline Memantine & $\begin{array}{l}\text { Oral, initially } 5 \mathrm{mg} \text { in the morning; increase } \\
\text { by } 5 \mathrm{mg} \text { daily each week if tolerated to a } \\
\text { maintenance dose of } 20 \mathrm{mg} \text { once daily }\end{array}$ \\
\hline
\end{tabular}

Doses should be reduced in severe renal impairment 
$(\mathrm{SMD}=0.28)$ and functional capacity $(\mathrm{SMD}=0.16)$ but not neuropsychiatric symptoms. ${ }^{17}$ A meta-analysis of 30 RCTs found memantine improved cognitive function and behavioural disturbances when compared with placebo. ${ }^{18}$ When compared with AChEI monotherapy, the combination of an AChEI and memantine led to modest improvement in cognition and global function at six months in people with advanced Alzheimer's disease. ${ }^{19}$ Whether these medications considerably improve long-term outcomes - such as the need for admission to residential aged care, maintaining critical activities of daily living, or quality of life - has not been shown. ${ }^{20}$
The response to antidementia medications varies, with up to $30-50 \%$ of people showing no benefit, while a smaller proportion (up to 20\%) may show a greater than average response..$^{21}$ This highlights the importance of individualising treatment decisions on the basis of clinical response and adverse events.

The Clinical practice guidelines for dementia in Australia recommend that before commencing therapy, an electrocardiogram, weight recording and falls risk assessment be conducted. ${ }^{15}$ The guidelines suggest that people who have been prescribed an AChEI or memantine should be reviewed shortly after initiation (eg one month) for assessment of adverse events and need for dose titration, and within six months to establish whether a clinically meaningful response to therapy exists. ${ }^{15}$ PBS-subsidised continuation beyond six months is dependent on the person having achieved a clinically meaningful response in terms of quality of life, cognition or behavioural symptoms. Cognitive function, caregiver impression of change, sleep, and behavioural and psychological symptoms of dementia (BPSD) should be assessed at each visit. Routine laboratory monitoring is not required for any of the antidementia medications.

Table 2. Summary of pharmacological treatment recommendations in Alzheimer's disease ${ }^{15,25}$

\begin{tabular}{ll}
\hline Stage & Recommendation \\
\hline $\begin{array}{l}\text { Newly diagnosed } \\
\text { mild-to-moderate } \\
\begin{array}{l}\text { Alzheimer's disease } \\
\text { Moderate-to-severe } \\
\text { dementia }\end{array}\end{array}$ & $\begin{array}{l}\text { Trial an AChEl } \\
\text { Donepezil, galantamine or rivastigmine chosen on the basis of ease of use, tolerability, cost, and clinician and } \\
\text { patient prefence, as efficacy appears to be similar }\end{array}$ \\
\hline Advanced dementia & $\begin{array}{l}\text { Continue memantine } \\
\text { In some people with advanced dementia it may be beneficial to discontinue administration of medications to } \\
\text { maximise quality of life and comfort. }\end{array}$
\end{tabular}

Behavioural and

psychological

symptoms

Antipsychotics

An antipsychotic should only be used if the following conditions are met: ${ }^{15}$

- Possible benefits and risks of treatment have been fully discussed with the patient and their family and/or carers. This should include assessment of cerebrovascular risk factors and a discussion about the possible increase in the risk of stroke and adverse effects on cognition.

- Target symptoms have been identified, quantified and documented

- Effects of comorbid conditions, such as depression, have been considered.

- An individual risk-benefit analysis has been undertaken to determine which agent is most suitable.

- Treatment is commenced with a low dose and titrated upwards if necessary.

- The patient is monitored for adverse events, including metabolic syndrome.

- Treatment is discontinued if no effect is seen within one to two weeks.

- If antipsychotics are used, choose an atypical or second-generation antipsychotic.

Treatment options* include:

- risperidone, doses not exceeding $1 \mathrm{mg}$ daily

- olanzapine, start at $2.5 \mathrm{mg}$ daily and titrated up to maximum of $5 \mathrm{mg}$ twice a day

- quetiapine, start at $25 \mathrm{mg}$ at bedtime and titrate up to a maximum of $75 \mathrm{mg}$ twice a day

Antidepressants Citalopram, start at $10 \mathrm{mg}$ daily and titrate up to maximum of $20 \mathrm{mg}$ daily

*Risperidone, limited to a maximum duration of 12 weeks, is the only antipsychotic currently listed for BPSD in Alzheimer's disease on the PBS AChEl, acetylcholinesterase inhibitor; BPSD, behavioural and psychological symptoms of dementia; PBS, Pharmaceutical Benefits Scheme 


\section{Medication management and adherence}

Alzheimer's disease is associated with medication management issues and low rates of adherence, with over $30 \%$ of people with dementia not taking their medications as intended. ${ }^{22}$ Examples of strategies to optimise medication use and adherence in people living with Alzheimer's disease are listed in Box 1.

\section{Discontinuing therapy}

The optimal duration of treatment with Alzheimer's disease medications is unclear, and an ongoing and individualised assessment of benefit and adverse events should be used to guide continuation. ${ }^{23}$ The recent Evidence-based clinical practice guideline for deprescribing cholinesterase inhibitors and memantine (the Guidelines) was based on a systematic review of international literature and endorsed by the National Health and Medical Research Council (NHMRC). The Guidelines recommend that for people taking an AChEI and/or memantine for longer than 12 months, a trial of discontinuation is considered if cognition and/or function has deteriorated significantly during the previous six months, if there was no benefit observed at any time during therapy, or if the person has severe or advanced dementia in which there is little hope of a meaningful benefit to continued therapy. ${ }^{24}$ Other reasons for discontinuation include poor tolerance despite dose reduction or medication switching, comorbidities or non-adherence that make continued use unacceptably risky or futile.

Unless there is an adverse drug reaction that necessitates rapid cessation, or the medication is already at the lowest dose, dosage should be tapered by half every four weeks to the lowest dose available before discontinuation, to minimise risk of dementia symptoms worsening during withdrawal. ${ }^{24}$ The medication should generally be re-introduced if a clinical decline occurs. If severe symptoms occur within one week of dose reduction/ cessation, this may indicate a withdrawal event related to discontinuation and the previous dose should be restarted. If symptoms occur within six weeks, this may indicate reccurrence of symptoms that were being managed by AChEI/ memantine and restarting the previous dose may be considered. ${ }^{24}$

\section{Other therapies}

Evidence is limited for other pharmacological approaches. These are summarised in Table $3 .^{25}$

\section{Management of BPSD}

BPSD is common in Alzheimer's disease, particularly in the mid-to-late stages, and contributes to admission to residential aged care and caregiver stress. These symptoms include agitation, aggression, hallucinations, delusions, depression, apathy, wandering, disinhibition and sleep disturbances. ${ }^{26}$ When a person with Alzheimer's disease develops BPSD, the first step is to identify possible precipitating factors and rule out or treat a medical cause (eg pain or infection) or superimposed delirium. ${ }^{26}$ Non-pharmacological interventions should be considered first, because pharmacological treatment for BPSD is not necessarily effective.

Prior to commencing pharmacological therapy, it is important to know which symptoms are being targeted for treatment. Although a drug may be indicated for BPSD management, this does not mean all symptoms are likely to respond equally well to that drug. ${ }^{27}$ When treating agitation in people with Alzheimer's disease, the Clinical practice guidelines for dementia in Australia suggest that a selective serotonin reuptake inhibitor (SSRI) may be trialled (the strongest evidence for effectiveness exists for citalopram) if non-pharmacological therapy has failed or is inappropriate. ${ }^{15}$ A recent network meta-analysis reported that SSRIs as a class had efficacy for alleviating agitation, but when analysed separately, citalopram was not significantly efficacious. ${ }^{28}$ Evaluation of efficacy and the potential for deprescribing should take place after two months. ${ }^{15}$ The time to onset of action, importance of adherence, and

\section{Box 1. Medication management strategies applicable to people living with Alzheimer's disease}

\section{Comprehensive medication review}

Identify medications, including over-the-counter products, that may worsen cognition or behaviours, in particular anticholinergic medications (eg antipsychotics, antidepressants, drugs for urinary incontinence, antihistamines)

Ensure the person with Alzheimer's disease and carers keep an up-to-date medication list including all prescription, over-the-counter and complementary medicines

Because the benefits of anti-dementia medications are modest, clinicians should assess whether the person is benefiting from the medication before persisting, and use caution to avoid prescribing cascades (eg the use of anticholinergics to treat urinary incontinence as an adverse effect of anticholinesterase inhibitor therapy)

\section{Adherence strategies ${ }^{35}$}

- Simplified administration instructions, including verbal, written and visual forms

- Dose administration aids (eg Webster-paks)

- Telephone follow-up

- Increased convenience (eg scheduled delivery of medications)

- Involving people with Alzheimer's disease, carers and family more in their care through self-monitoring

- Simplified dosing regimens

- Adjustment of the regimen to complement daily habits

- Medication charts

- Unit-dose dispensing

- Reminders (eg appointments and prescription refills, medication packaging)

- Minimising generic substitution

- Direct observation of administration 


\section{Table 3. Other therapies for Alzheimer's disease}

\begin{tabular}{lll}
\hline Therapy & Main concept & Key evidence \\
\hline $\begin{array}{ll}\text { Oestrogen } \\
\text { therapy }\end{array}$ & $\begin{array}{l}\text { Enhances cerebral blood flow, } \\
\text { prevents atrophy of cholinergic } \\
\text { neurons, reduces oxidative } \\
\text { stress, and modulates the effects } \\
\text { of nerve growth factors }\end{array}$ & $\begin{array}{l}\text { A systematic review }{ }^{36} \text { of seven } \\
\text { RCTs including } 351 \text { women } \\
\text { with Alzheimer's disease found } \\
\text { treatment with oestrogen did not } \\
\text { improve cognitive or functional } \\
\text { outcomes compared with } \\
\text { placebo. }\end{array}$
\end{tabular}

\begin{tabular}{ll}
\hline Anti- & Reduces intraneuronal \\
inflammatory & oligomeric amyloid-beta peptide, \\
drugs & $\begin{array}{l}\text { reduces cognitive deficits and } \\
\text { prevents hyperphosphorylated } \\
\text { tau immunoreactivity }\end{array}$
\end{tabular}

Gingko biloba Enhances blood flow and reduces density of oxygen free radicals

\section{A systematic review ${ }^{37}$ of 14 RCTs} of aspirin, steroids and NSAIDs found no benefit in cognition in people with Alzheimer's disease, but found increased risk of adverse events.

\section{A systematic review ${ }^{38}$ of 36} studies of ginkgo for cognitive impairment and dementia concluded that ginkgo biloba, while safe, has inconsistent and unconvincing evidence of benefit.

\begin{tabular}{ll}
\hline Statins & Decreases cholesterol \\
& concentration/pleiotropic effects \\
& (lowers amyloid-beta peptide \\
& production)
\end{tabular}

Vitamin E Antioxidant properties
(alpha

\section{Conflicting evidence. A} meta-analysis ${ }^{39}$ of four RCTs ( $n=1154$ ) found statins do not have any benefit on cognitive outcomes in Alzheimer's disease.

Conflicting evidence. A systematic review ${ }^{40}$ of one RCT $(n=304)$ of vitamin $E$ in people with Alzheimer's disease found modest benefit in delaying functional progression, with no measurable effect on cognitive performance.

Major adverse effects/ Recommendation
precautions

Cardiovascular events, breast and endometrial cancer

No current evidence for the routine initiation of oestrogen therapy in people with established Alzheimer's disease; may actually be harmful
Gl bleeding, renal impairment, cardiovascular events

Antiplatelet effects and risk of bleeding with other drugs that increase haemorrhagic risk
No current evidence for the routine initiation of NSAIDs in people with Alzheimer's disease with no other indication

Avoid as questionable efficacy and lack of regulation, including variability in the dosing and contents of herbal extracts

Myopathy and rhabdomyolysis, diabetes, elevated aminotransferase

No current evidence for the routine initiation of statins in people with Alzheimer's disease with no other indication

Inconsistent evidence that high-dose vitamin E is

Use with caution given associated with increased cardiovascular outcomes limited efficacy and and mortality potential adverse events
A meta-analysis ${ }^{41}$ of five RCTs concluded that vitamin $B$ and folic acid supplementation does not stabilise or slow decline in cognition, function, behaviour and global change. may be increased in

Alzheimer's disease, and hyperhomocysteinemia may contribute to disease pathophysiology by vascular and direct neurotoxic mechanisms

$\begin{array}{ll}\text { Omega-3 } & \text { DHA is the most abundant long } \\ \text { fatty acids } & \text { chain polyunsaturated fatty acid } \\ & \text { in the brain. Epidemiologic and } \\ & \text { animal studies suggest dietary } \\ & \text { fish or fish oil rich in omega-3 } \\ & \text { fatty acids may prevent } \\ & \text { Alzheimer's disease }\end{array}$

Souvenaid

Patented combination of nutrients, including uridine monophosphate, choline, omega-3 fatty acids, phospholipids, vitamin C, vitamin $E$, selenium, vitamin $B 6$, vitamin B12 and folic acid important for brain health

\section{A systematic review ${ }^{42}$ of} three RCTs of omega-3 fatty acid supplementation in 632 people with mild-to-moderate Alzheimer's disease found no effect on cognitive and functional decline
Few adverse effects

No current evidence for the routine initiation of vitamin B supplementation in people with Alzheimer's disease
Few adverse effects; high doses may increase bleeding time
No current evidence for the routine initiation of omega-3 fatty acid supplementation in people with Alzheimer's disease

\author{
Few adverse effects \\ No current evidence for \\ the routine initiation of \\ Souvenaid in people with \\ Alzheimer's disease
}


risk of withdrawal and possible adverse effects should be explained at initiation. Antidepressants with anticholinergic properties (eg tricyclics) should be avoided because of the potential for cognitive worsening. ${ }^{15}$

There is uncertainty about the use of antidepressants in the treatment of depression in Alzheimer's disease. A meta-analysis of six RCTs found no clear evidence to support the efficacy of antidepressants for treating depression in Alzheimer's disease. ${ }^{29}$ There are also concerns that they may increase the risk of mortality, although the evidence for this is inconclusive. ${ }^{30}$ Despite the uncertainties, the Guidelines recommend that people with Alzheimer's disease who develop major depression and have a pre-existing history of major depression prior to Alzheimer's disease development should receive usual antidepressant therapy. ${ }^{15}$

Antipsychotics should generally be avoided in people with Alzheimer's disease because of the increased risk of stroke, death and cognitive worsening. ${ }^{31}$ However, the Guidelines suggest patients may trial an antipsychotic if they have severe BPSD (ie psychosis and/or agitation or aggression) that results in considerable distress to themselves or others. ${ }^{15}$ Atypical or second-generation antipsychotics with less tendency to cause extrapyramidal adverse effects are recommended. Patients should be started on a low dose and closely monitored for adverse effects (Table 2). For the treatment of psychosis, risperidone has been reported to have the strongest evidence. ${ }^{32}$ For treating agitation/ aggression, risperidone and olanzapine have the strongest evidence, while weaker evidence exists for aripiprazole. ${ }^{28}$ Olanzapine and quetiapine have been reported to have the best tolerability. ${ }^{15}$ The only antipsychotic currently listed on the PBS for BPSD, including psychotic symptoms and agitation, is risperidone. Review of antipsychotic treatment should occur every four to 12 weeks, considering ongoing need and potential for discontinuation. ${ }^{15}$ Patients should be assessed regularly for changes in target symptoms and cognition, and these should be recorded. AChEIs may produce some small benefits in BPSD; however, these are unlikely to be clinically significant. ${ }^{17,33}$ Most mood stabilisers have not been trialled as treatments of BPSD, and limited evidence suggests mood stabilisers are ineffective in managing BPSD. ${ }^{34}$ Table 2 reports the conditions for prescribing psychotropics in Alzheimer's disease and recommended treatment regimens.

Where severe BPSD places people with dementia or others at risk, referral to specialist services for BPSD management should be made. ${ }^{15}$

\section{Summary}

AChEIs or memantine may be trialled in people with Alzheimer's disease, to delay cognitive and functional decline. The choice of pharmacological agents is based on the stage of Alzheimer's disease, tolerability, adverse effect profile, ease of use and cost. BPSD is common in people with Alzheimer's disease and may respond to symptomatic treatment. Dementia Australia can provide information and assistance with other treatments, support services and education (www.dementia.org.au).

\section{Authors}

Edwin CK Tan, BPharm (Hons), PhD, NHMRC-ARC Dementia Research Development Fellow, Centre for Medicine Use and Safety, Faculty of Pharmacy and Pharmaceutical Sciences, Monash University, Parkville, Vic; Aging Research Center, Department of Neurobiology, Care Sciences and Society, Karolinska Institutet and Stockholm University, Stockholm, Sweden.edwin.tan@monash.edu

Sarah N Hilmer, MBBS (Hons) FRACP, PhD, Head of Department of Clinical Pharmacology and Senior Staff Specialist Aged Care, Kolling Institute, Royal North Shore Hospital, and Conjoint Professor of Geriatric Pharmacology, University of Sydney,

St Leonards, NSW, Australia; NHMRC Cognitive Decline Partnership Centre, Hornsby Ku-ring-gai Hospital, Hornsby, NSW

Sara Garcia-Ptacek, MD, PhD, Postdoctoral Fellow, Division of Clinical Geriatrics, Department of Neurobiology, Care Sciences and Society, Karolinska Institutet, Stockholm, Sweden; Neurology Section, Department of Internal Medicine, Södersjukhuset, Stockholm, Sweden

J Simon Bell, BPharm (Hons), PhD, NHMRC Dementia Leadership Fellow, Centre for Medicine Use and Safety, Faculty of Pharmacy and Pharmaceutical Sciences, Monash University, Parkville, Vic; NHMRC Cognitive Decline Partnership Centre, Hornsby Ku-ring-gai Hospital, Hornsby, NSW, Australia; School of Pharmacy and Medical Sciences, University of South Australia, Adelaide, SA

Competing interests: None

Funding: ECKT is supported by an NHMRC-ARC Dementia Research Development Fellowship. SG-P is supported by grants from FORTE, Loo and
Hans Osterman's Foundation, Karolinska Institutet Research Foundations, Swedish Stroke Association and Swedish Order of St John. JSB is supported by an NHMRC Dementia Leadership Fellowship. Provenance and peer review: Commissioned, externally peer reviewed.

\section{References}

1. Dementia Australia. Dementia statistics. Dementia Australia, 2018. Available at https://www.dementia. org.au/statistics [Accessed 14 June 2018].

2. The National Centre for Social and Economic Modelling. Economic Cost of Dementia in Australia 2016-2056. Canberra: NATSEM, 2017.

3. Australian Bureau of Statistics. Causes of Death, Australia, 2016. Cat. no. 3303.0. Canberra: ABS, 2017.

4. Dementia Australia. Alzheimer's disease. Dementia Australia, 2018. Available at https:// www.dementia.org.au/about-dementia/typesof-dementia/alzheimers-disease [Accessed 26 March 2018].

5. Querfurth HW, LaFerla FM. Alzheimer's disease. N Engl J Med 2010 28;362(4):329-44. doi:10.1056/ NEJMra0909142.

6. Hansen RA, Gartlehner G, Webb AP, Morgan LC, Moore CG, Jonas DE. Efficacy and safety of donepezil, galantamine, and rivastigmine for the treatment of Alzheimer's disease: A systematic review and meta-analysis. Clinical Interv Aging 2008;3(2):211-25.

7. Spalletta G, Caltagirone C, Padovani A, et al. Cognitive and affective changes in mild to moderate Alzheimer's disease patients undergoing switch of cholinesterase inhibitors: A 6-month observational study. PLoS One 2014;9(2):e89216. doi:10.1371/journal.pone.0089216.

8. Bartorelli L, Giraldi C, Saccardo M, et al. Effects of switching from an AChE inhibitor to a dual AChEBuChE inhibitor in patients with Alzheimer's disease. Curr Med Res Opin 2005;21(11):1809-18.

9. Australian Medicines Handbook. Adelaide: $\mathrm{AMH}$ Pty Ltd, 2018.

10. Sink KM, Thomas J, Xu H, Craig B, Kritchevsky S, Sands LP. Dual use of bladder anticholinergics and cholinesterase inhibitors: Long-term functional and cognitive outcomes. J Am Geriatr Soc 2008;56(5):847-53. doi:10.1111/j.15325415.2008.01681.x

11. Boudreau DM, Yu O, Gray SL, Raebel MA, Johnson J, Larson EB. Concomitant use of cholinesterase inhibitors and anticholinergics: Prevalence and outcomes. J Am Geriatr Soc 2011;59(11):2069-76. doi:10.1111/j.15325415.2011.03654.x.

12. Kim DH, Brown RT, Ding EL, Kiel DP, Berry SD. Dementia medications and risk of falls, syncope, and related adverse events: Meta-analysis of randomized controlled trials. J Am Geriatr Soc 2011;59(6):1019-31. doi:10.1111/j.15325415.2011.03450.x.

13. Ali TB, Schleret TR, Reilly BM, Chen WY, Abagyan R. Adverse effects of cholinesterase inhibitors in dementia, according to the pharmacovigilance databases of the United-States and Canada. PLoS One 2015;10(12):e0144337.

14. Olivares D, Deshpande VK, Shi Y, et al. N-Methyl D-Aspartate (NMDA) receptor antagonists and memantine treatment for Alzheimer's disease, vascular dementia and Parkinson's disease. Curr Alzheimer Red 2012:9(6):746-58. 
15. Guideline Adaptation Committee. Clinical practice guidelines and principles of care for people with dementia. Sydney: NHMRC Cognitive Decline Partnership Centre, 2016.

16. Raina $P$, Santaguida $P$, Ismaila $A$, et al. Effectiveness of cholinesterase inhibitors and memantine for treating dementia: Evidence review for a clinical practice guideline. Ann Intern Med 2008;148(5):379-97.

17. Blanco-Silvente $L$, Castells $X$, Saez M, et al. Discontinuation, efficacy, and safety of cholinesterase inhibitors for Alzheimer's disease: A meta-analysis and meta-regression of 43 randomized clinical trials enrolling 16106 patients. Int J Neuropsychopharmacol 2017 Jul 1;20(7):51928. doi:10.1093/ijnp/pyx012.

18. Kishi T, Matsunaga S, Oya K, Nomura I, Ikuta T, Iwata N. Memantine for Alzheimer's disease: An updated systematic review and meta-analysis. J Alzheimers Dis 2017;60(2):401-25. doi:10.3233/ JAD-170424.

19. Chen R, Chan PT, Chu H, et al. Treatment effects between monotherapy of donepezil versus combination with memantine for Alzheimer disease: A meta-analysis. PLoS One 2017;12(8):e0183586. doi:10.1371/journal. pone.0183586.

20. Courtney C, Farrell D, Gray R, et al. Long-term donepezil treatment in 565 patients with Alzheimer's disease (AD2000): Randomised double-blind trial. Lancet 2004 Jun 26;363(9427):2105-15.

21. Grossberg GT, Desai AK. Management of Alzheimer's disease. J Gerontol A Biol Sci Med Sci 2003 Apr;58(4):331-53.

22. Smith D, Lovell J, Weller C, et al. A systematic review of medication non-adherence in persons with dementia or cognitive impairment. PLoS One 2017;12(2):e0170651.

23. Livingston G, Sommerlad A, Orgeta V, et al. Dementia prevention, intervention, and care. Lancet 2017;390(10113):2673-734. doi:10.1016/ S0140-6736(17)31363-6.

24. Reeve E, Farrell B, Thompson W, et al. Evidencebased clinical practice guideline for deprescribing cholinesterase inhibitors and memantine. Sydney: University of Sydney, 2018.

25. Press D, Alexander M. Treatment of dementia. UpToDate 2018. Available at https://www. uptodate.com/contents/treatment-of-dementia [Accessed 15 June 2018].

26. Press D, Alexander M. Management of neuropsychiatric symptoms of dementia. UpToDate 2018. Available at https://www. uptodate.com/contents/management-ofneuropsychiatric-symptoms-of-dementia [Accessed 15 June 2018].

27. Macfarlane S, O'Connor D. Managing behavioural and psychological symptoms in dementia. Australian Prescriber 201639(4):123-25. doi:10.18773/austprescr.2016.052.

28. Kongpakwattana K, Swangjit R, Tawankanjanachot I, Bell JS, Hilmer SN, Chaiyakunapruk N. Pharmacological treatments for alleviating agitation in dementia: A systematic review and network meta-analysis. $\mathrm{Br} \mathrm{J} \mathrm{Clin}$ Pharmacol 2018 84(7):1445-56. doi:10.1111/ bcp.13604.

29. Orgeta V, Tabet N, Nilforooshan R, Howard R. Efficacy of antidepressants for depression in Alzheimer's disease: Systematic review and metaanalysis. J Alzheimers Dis 2017;58(3):725-33. doi:10.3233/JAD-161247.
30. Mueller C, Huntley J, Stubbs B, et al. Associations of neuropsychiatric symptoms and antidepressant prescription with survival in Alzheimer's disease. J Am Med Dir Assoc 2017;18(12):1076-81. doi:10.1016/j.jamda.2017.07.001.

31. Ballard C, Hanney ML, Theodoulou M, et al. The dementia antipsychotic withdrawal trial (DART-AD): Long-term follow-up of a randomised placebo-controlled trial. Lancet Neurol 2009;8(2):151-7. doi: 10.1016/S14744422(08)70295-3.

32. Katz I, de Deyn PP, Mintzer J, Greenspan A, Zhu Y, Brodaty $\mathrm{H}$. The efficacy and safety of risperidone in the treatment of psychosis of Alzheimer's disease and mixed dementia: A meta-analysis of 4 placebo-controlled clinical trials. Int J Geriatr Psychiatry 2007;22(5):475-84.

33. Wang J, Yu JT, Wang HF, et al. Pharmacological treatment of neuropsychiatric symptoms in Alzheimer's disease: A systematic review and meta-analysis. J Neurol Neurosurg Psychiatry 2015;86(1):101-9. doi:10.1136/jnnp-2014-308112.

34. Gallagher D, Herrmann N. Antiepileptic drugs for the treatment of agitation and aggression in dementia: Do they have a place in therapy? Drugs 2014;74(15):1747-55. doi: 10.1007/s40265-0140293-6.

35. Arlt S, Lindner R, Rosler A, von RentelnKruse W. Adherence to medication in patients with dementia: Predictors and strategies for improvement. Drugs Aging 2008;25(12):1033-47. doi: 10.2165/0002512-200825120-00005.

36. Hogervorst E, Yaffe K, Richards M, Huppert FA. Hormone replacement therapy to maintain cognitive function in women with dementia. Cochrane Database Syst Rev 2009;(1):Cd003799. doi: 10.1002/14651858.CD003799.pub2.

37. Jaturapatporn D, Isaac MG, McCleery J, Tabet N. Aspirin, steroidal and non-steroidal anti-inflammatory drugs for the treatment of Alzheimer's disease. Cochrane Database Syst Rev 2012;(2):Cd006378. doi: 10.1002/14651858. CD006378.pub2.

38. Birks J, Grimley Evans J. Ginkgo biloba for cognitive impairment and dementia. Cochrane Database Syst Rev 2009;(1):Cd003120. doi: 10.1002/14651858.CD003120.pub3.

39. McGuinness B, Craig D, Bullock R, Malouf R, Passmore P. Statins for the treatment of dementia. Cochrane Database Syst Rev 2014;(7):Cd007514. doi:10.1002/14651858. CD007514.pub3.

40. Farina N, Llewellyn D, Isaac MG, Tabet N. Vitamin E for Alzheimer's dementia and mild cognitive impairment. Cochrane Database Syst Rev 2017;1:Cd002854. doi: 10.1002/14651858. CD002854.pub4.

41. Li MM, Yu JT, Wang HF, et al. Efficacy of vitamins B supplementation on mild cognitive impairment and Alzheimer's disease: A systematic review and meta-analysis. Curr Alzheimer Res 2014;11(9):844-52.

42. Burckhardt M, Herke M, Wustmann T, Watzke S, Langer G, Fink A. Omega-3 fatty acids for the treatment of dementia. Cochrane Database Syst Rev 2016;4:Cd009002. doi: 10.1002/14651858. CD009002.pub3.

43. Onakpoya IJ, Heneghan CJ. The efficacy of supplementation with the novel medical food, Souvenaid, in patients with Alzheimer's disease: A systematic review and meta-analysis of randomized clinical trials. Nutr Neurosci 2017;20(4):219-27. doi: 10.1080/1028415X.2015.1110899. 